УдК 797.212

ISSN (Ukrainian ed. Print) 1991-0177 ISSN (Ukrainian ed. Online) 1999-818X 2021, № 6(86), C.32-38 doi:10.15391/snsv.2021-6.005

\title{
Визначення модельних характеристик техніко-тактичних показників висококваліфікованих плавчинь, що спеціалізуються на дистанції 50 метрів різними способами
}

\author{
Ольга Пилипко \\ Аліна Пилипко \\ Аліна Шинкаренко
}

Харківська державна академія фізичної культури, Харків, Україна

Мета: розробити модельні характеристики техніко-тактичних показників висококваліфікованих плавчинь, що спеціалізуються на дистанції 50 метрів різними способами.

Матеріал і методи: аналіз літературних джерел, хронометрування, відеозйомка, методи математичної статистики. Досліджуваний контингент склали учасниці фінальних запливів Чемпіонатів та Кубків України з плавання на дистанції 50 метрів різними способами. Рівень спортивної кваліфікації спортсменок відповідав званням Майстер спорту України і Майстер спорту України міжнародного класу.

Результати: досліджено вплив показників швидкості плавання, темпу та «кроку» циклу гребкових рухів на результат подолання спортсменками високої кваліфікації дистанції 50 метрів різними способами; визначено найбільш значущі параметри техніко-тактичної майстерності висококваліфікованих плавчинь, в залежності від способу плавання та розроблено їх модельні характеристики.

Висновки: вплив показників швидкості плавання, темпу та «кроку» циклу гребкових рухів на результат подолання спортсменками високої кваліфікації дистанції 50 метрів має характерні особливості в залежності від способу плавання. Найбільш значущими техніко-тактичними параметрами у способі плавання «кроль на грудях» $\epsilon$ швидкість на ділянках «15 м - 25 м» та «45 м - 50 м», темп гребкових рухів на відрізку «35 м - 45 м» (R дорівнює -0,60, -0,72 та -0,72 відповідно). В «кролі на спині» результат переважно залежить від швидкого пропливання перших 35 метрів дистанції (показники $R$ знаходяться в межах -0, 57 - -0, 98), а також значень темпу на ділянці «25 м - 35 м» $(R=-0,50)$. Результативність на дистанції 50 м при плаванні способом «брас» знаходиться під впливом показників швидкості подолання відрізків «винирювання - 15 м», «25 м - 35 м» та «45 м - 50 м», темпу гребкових рухів на ділянках «винирювання - 15 м» та «15 м - 25 м», здатності зберігати великий «крок» на відрізках «15 м - 25 м» та «25 м - 35 м» ( $R$ на рівні значень -0,88, -0,56, -0,86, -0,55, -0,70, 0,79 та -0,69 відповідно). Результат в способі плавання «батерфляй» більшою мірою зумовлений швидкістю проходження підводної ділянки та другої половини дистанції 50 метрів ( $R$ в межах 0,58, - 0,86). Темп $i$ «крок» циклу гребкових рухів тісно корелює з кінцевим результатом на другій половині змагальної дистанції (значення $R$ варіюють від -0,70 до -0,97). Орієнтація на розроблені модельні характеристики найбільш значущих показників техніко-тактичної майстерності спортсменок високої кваліфікації, що мають різну плавальну спеціалізацію, сприятиме вдосконаленню тренувальної та змагальної діяльності у сучасному плаванні.

Ключові слова: спортсменки, 50 метрів, способи плавання, техніко-тактичні показники, взаємозв'язок, модельні характеристики.

\section{Вступ}

Рівень розвитку сучасного плавання, для якого характерна демонстрація високих результатів, розширення арсеналу дистанцій, на яких виступають спортсмени, диктує необхідність пошуку шляхів вдосконалення тренувальної та змагальної діяльності [1; 7].

Значна роль в цьому напрямку відводиться аналізу змагальної діяльності висококваліфікованих спортсменів, вивченню широкого кола питань, пов'язаних з їїіндивідуалізацією та оптимізацією [3; 6].

На сьогоднішній день завдяки численним науковим доробкам визначені основні компоненти структури зма- гальної діяльності, виявлена ступінь зв'язку між ними та різними параметрами структури спеціальної підготовленості плавців, тощо [2; 9].

Особливий інтерес серед досліджуваних показників викликають параметри техніко-тактичної майстерності спортсменок, які є своєрідним відображенням здатності реалізувати результати проведеної роботи в умовах змагань [5; 8; 11; 12].

Однак слід зазначити, що увага фахівців переважно зосереджена на вивченні особливостей технікотактичних дій спортсменок при пропливанні змагальних дистанцій способом «кроль на грудях», в той час 


\section{СЛОБОЖАНСЬКИЙ НАУКОВО-СПОРТИВНИЙ ВІСНИК}

як нюанси подолання дистанцій іншими спортивними способами залишаються розглянутими не в повному обсязі [4; 10].

У сучасній літературі недостатньо робіт, які пов'язані з порівняльним аналізом параметрів техніко-тактичної майстерності плавчинь під час проходження дистанцій різної довжини з урахуванням віку, способу плавання, рівня спортивної кваліфікації, визначенням їх модельних характеристик.

Проведення досліджень у цьому напрямку дозволить обґрунтовано підходити до диференціювання підготовки спортсменок різних плавальних спеціалізацій, що в свою чергу буде сприяти поліпшенню якості їх тренувального процесу, підвищить ефективність виступу на змаганнях.

Мета роботи - розробити модельні характеристики техніко-тактичних показників висококваліфікованих плавчинь, що спеціалізуються на дистанції 50 метрів різними способами.

\section{Завдання дослідження:}

1. Дослідити вплив показників швидкості, темпу та «кроку» циклу гребкових рухів на результат подолання спортсменками високої кваліфікації дистанції 50 метрів різними способами.

2. Визначити найбільш значущі параметри техніко-тактичної майстерності висококваліфікованих плавчинь в залежності від способу плавання.

3. Розробити модельні характеристики технікотактичних показників спортсменок високої кваліфікації при пропливанні найбільш значущих ділянок дистанції 50 метрів різними способами.
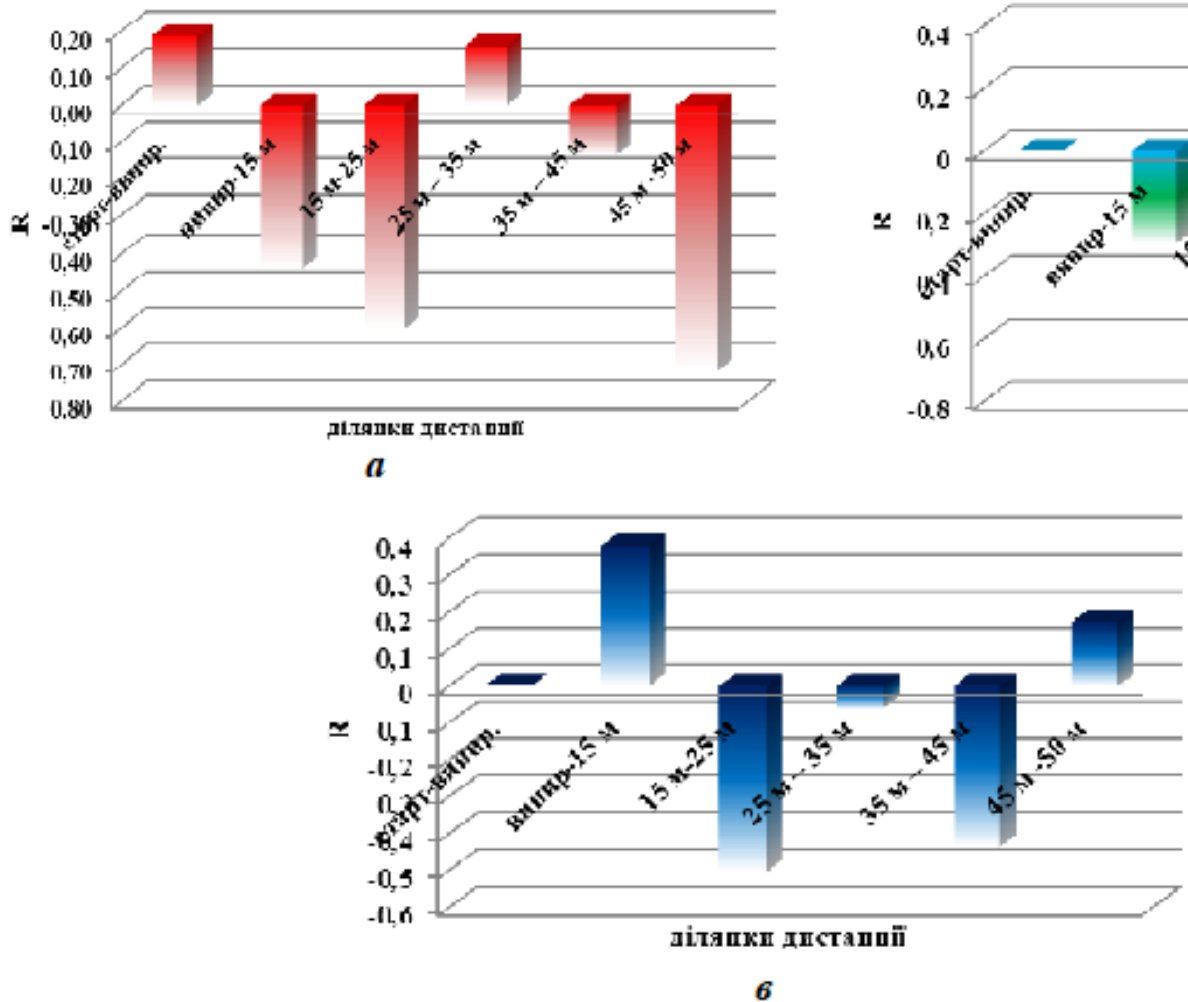

Рис. 1. Вплив техніко-тактичних показників висококваліфікованих спортсменок під час подолання різних ділянок дистанції 50 метрів способом «кроль на грудях» на кінцевий результат: а - швидкість, б - темп, в - «крок» циклу гребкових рухів

\section{Матеріал і методи дослідження}

Для вирішення поставлених завдань були використані наступні методи: аналіз літературних джерел, хронометрування, відеозйомка, методи математичної статистики.

Обстежувана група складалася з учасниць фінальних запливів Чемпіонатів і Кубків України з плавання на дистанції 50 метрів в способах «кроль на грудях», «кроль на спині», «брас» та «батерфляй». Рівень спортивної кваліфікації спортсменок відповідав званням Майстер спорту України і Майстер спорту України міжнародного класу.

\section{Результати дослідження}

Для розробки модельних характеристик технікотактичних показників висококваліфікованих плавчинь, що спеціалізуються на дистанції 50 метрів різними способами, нами була досліджена ступінь кореляційного взаємозв'язку між параметрами швидкості, темпу і «кроку» циклу гребкових рухів та кінцевим результатом пропливання даної змагальної дистанції способами «кроль на грудях», «кроль на спині», «брас» і «батерфляй».

Проведений аналіз отриманих даних дозволив визначити, що у способі плавання «кроль на грудях» найбільш значущими для досягнення високих результатів на дистанції 50 метрів є параметри швидкості на відрізках «15 м - 25 м» та «45 м - 50 м» (R дорівнює -0,60 та -0,72 відповідно) (рис. 1 а).

Тісний кореляційний взаємозв'язок з результатом має темп гребкових рухів на відрізку «35 м - 45 м» (R= $-0,72)$ (рис. 1 б).

Суттєво впливає на кінцевий результат параметр «кроку» циклу гребкових рухів на ділянці «15 м - 25 м» $(R=-0,50)$ (рис. 1 в).

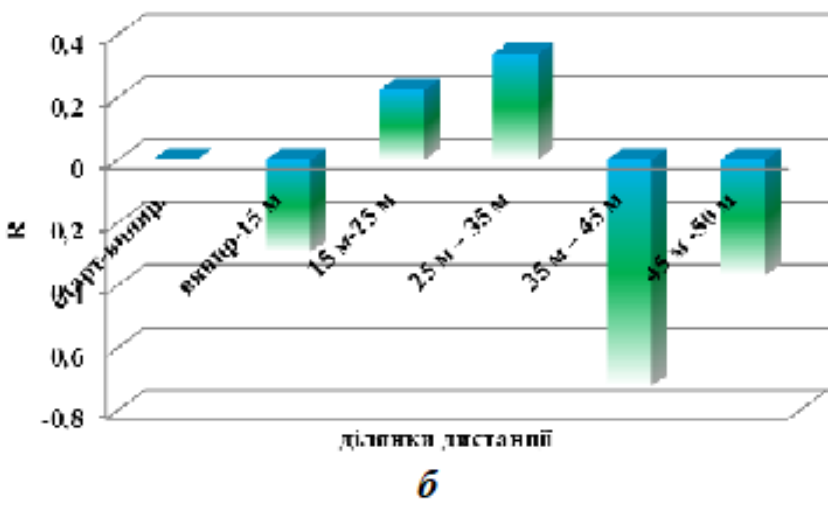



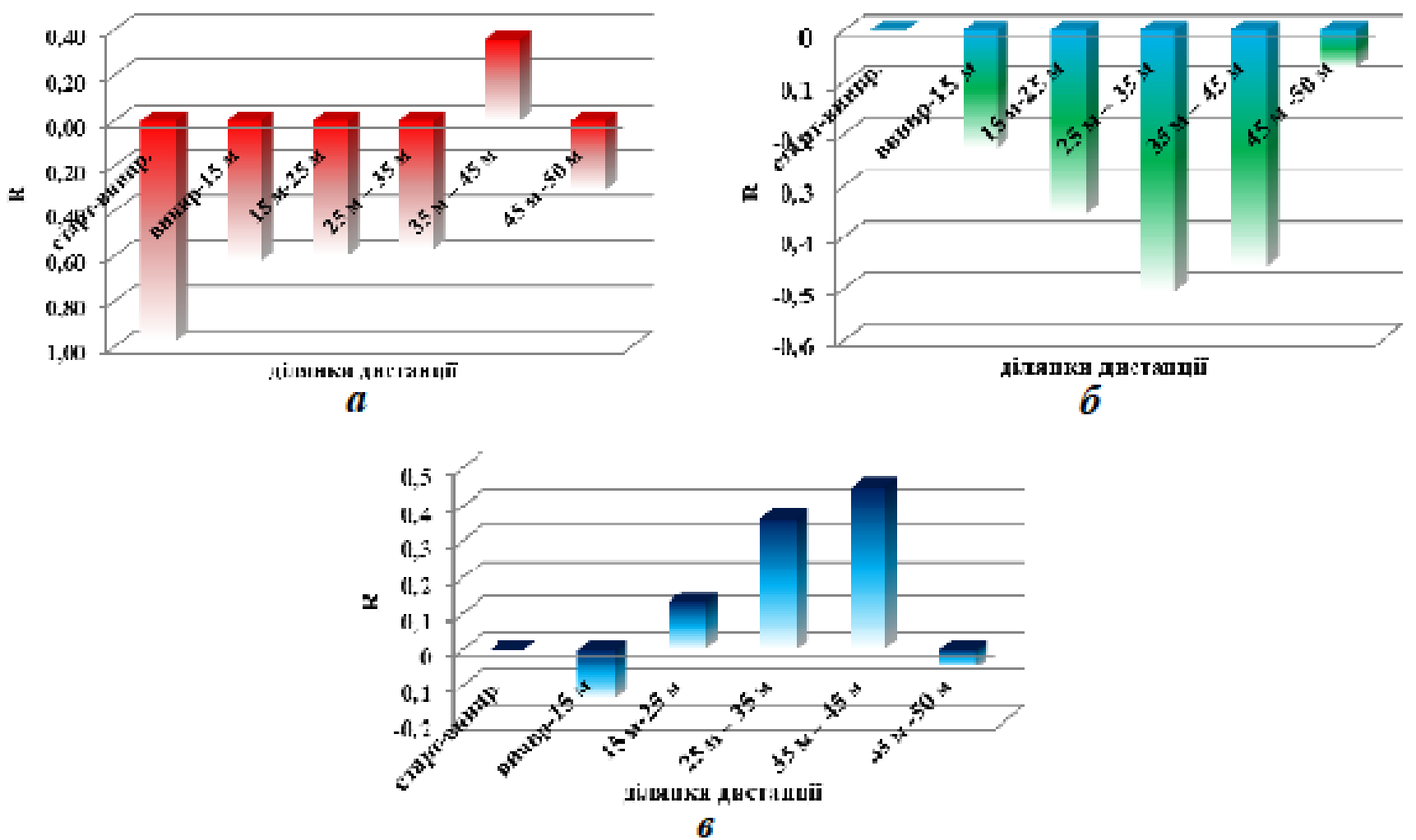

Рис. 2. Вплив техніко-тактичних показників висококваліфікованих спортсменок під час подолання різних ділянок дистанції 50 метрів способом «кроль на спині» на кінцевий результат: a - швидкість, б - темп, в - «крок» циклу гребкових рухів

У способі плавання «кроль на спині» результат більшою мірою залежить від швидкого проходження перших 35 метрів дистанції (значення R варіюють в межах -0, 57 - -0, 98) (рис. 2 а). При чому по мірі пропливання дистанції вплив швидкісних параметрів неухильно знижується. Тому спортсменкам слід випереджати суперниць саме на першій половині дистанції, особливо під час подолання відрізку «старт-винирювання».

Серед інших техніко-тактичних показників у спиністок значущим $€$ темп на ділянці «25 м - 35 м» $(R=-0,50)$ (рис. 2 б).

В свою чергу «крок» циклу гребкових рухів при плаванні на спині на найкоротшій у цьому способі змагальній дистанції є незначним за ступенем значущості (рис. 2 в).

При плаванні способом «брас» результативність на дистанції 50 метрів залежить від швидкості подолання спортсменками ділянок «винирювання - 15 м», «25 м 35 м» та «45 м - 50 м» (R дорівнює -0,88, -0,56 та -0,86 відповідно) (рис. 3 а).

Значний вплив на результат чинить темп гребкових рухів, який демонструють висококваліфіковані брасистки на відрізках «винирювання - 15 м» та «15 м - 25 м» (R знаходиться на рівні значень $-0,55$ та $-0,70$ відповідно) (рис. 3 б).

Велике значення має здатність спортсменок зберігати великий «крок» на ділянках дистанційного плавання, а саме в межах «15 м - 25 м» і «25 м - 35 м». Значення коефіцієнта кореляції сягає величин 0,79 і -0,69 (рис. 3 в).

Результат в способі плавання «батерфляй» зумовлений швидкістю подолання підводної ділянки та другої половини змагальної дистанції 50 метрів ( $\mathrm{R}$ дорівнює $0,58-0,86)$ (рис. 4 a).

У цьому найбільш складному з точки зору силової та функціональної підготовленості способі плавання значну роль відіграє здатність спортсменки зберігати стабільні показники темпу гребкових рухів на другій половині дистанції. При наближенні до фінішної позначки вплив темпових показників на результат посилюється. Значення R збільшуються 3 -0,70 до -0,97 (рис. 4 б).

«Крок» циклу гребкових рухів, так само як і темп, має тісний кореляційний зв'язок з результатом на другій половині дистанції 50 метрів ( $R$ знаходиться на рівні значень 0,83 та 0,90 відповідно) (рис. 4 в).

Таким чином, можна стверджувати, що проходження плавчинями високого класу другої половини дистанції 50 метрів способом «батерфляй» на значній швидкості з утриманням високих показників темпу рухів та довжини гребка дозволить демонструвати гарні результати та досягти успіху на змаганнях.

Спираючись на виявлені кореляційні зв'язки, нами були розроблені модельні значення найбільш вагомих показників техніко-тактичної майстерності висококваліфікованих спортсменок, які успішно долають дистанцію 50 метрів різними способами плавання (табл. 1).

Розроблені модельні характеристики можуть бути використані в якості орієнтирів для вдосконалення тренувальної та змагальної діяльності висококваліфікованих спортсменок різних плавальних спеціалізацій. 


\section{СЛОБОЖАНСЬКИЙ НАУКОВО-СПОРТИВНИЙ ВІСНИК}
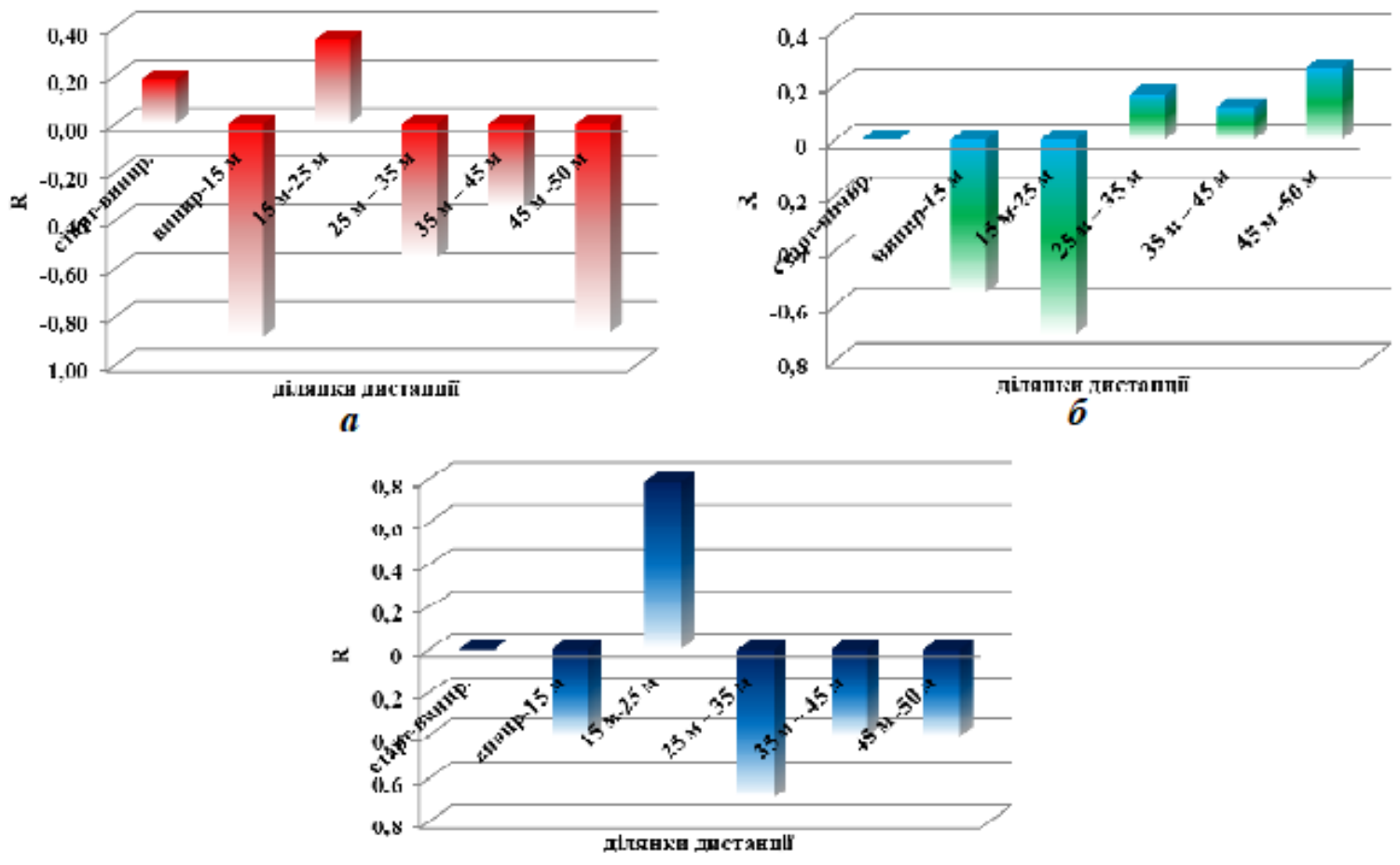

6

Рис. 3. Вплив техніко-тактичних показників висококваліфікованих спортсменок під час подолання різних ділянок дистанції 50 метрів способом «брас» на кінцевий результат: а - швидкість, б - темп, в - «крок» циклу гребкових рухів
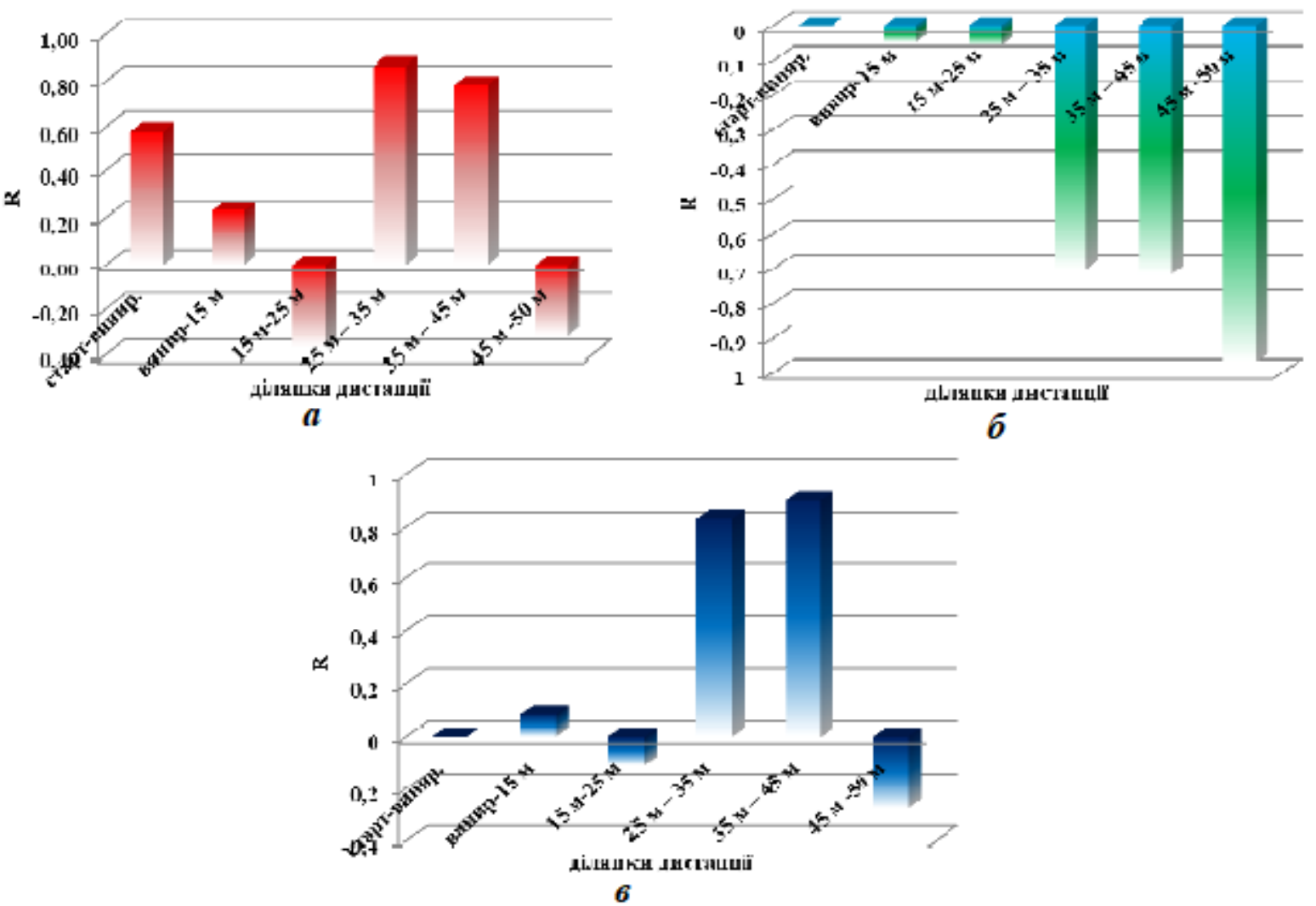

Рис. 4. Вплив техніко-тактичних показників висококваліфікованих спортсменок під час подолання різних ділянок дистанції 50 метрів способом «батерфляй» на кінцевий результат: а - швидкість, б - темп, в - «крок» циклу гребкових рухів 


\begin{abstract}
Таблиця 1
Модельні характеристики показників техніко-тактичної майстерності спортсменок високої кваліфікації при подоланні найбільш значущих ділянок змагальної дистанції 50 метрів різними способами плавання
\end{abstract}

\begin{tabular}{|c|c|c|c|c|}
\hline \multirow{2}{*}{$\begin{array}{l}\text { № } \\
3 / \text { II }\end{array}$} & \multirow[t]{2}{*}{ Ділянки змагальної дистанції } & \multicolumn{3}{|c|}{$\begin{array}{l}\text { Модельні значення показників } \\
\text { техніко-тактичної майстерності }\end{array}$} \\
\hline & & Швидкість & Темп & «Крок» \\
\hline \multicolumn{5}{|c|}{ Кроль на грудях } \\
\hline 1. & $15 \mathrm{M}-25 \mathrm{M}$ & $1,90 \pm 0,23$ & $58,98 \pm 7,61$ & $1,80 \pm 0,14$ \\
\hline 2. & $35 \mathrm{M}-45 \mathrm{M}$ & $1,75 \pm 0,11$ & $56,07 \pm 10,40$ & $1,90 \pm 0,18$ \\
\hline 3. & $45 \mathrm{~m}-50 \mathrm{M}$ & $1,62 \pm 0,26$ & $63,60 \pm 10,27$ & $1,70 \pm 8,11$ \\
\hline \multicolumn{5}{|c|}{ Кроль на спині } \\
\hline 4. & старт-винирювання & $2,06 \pm 0,13$ & - & - \\
\hline 5. & винирювання-15 м & $1,65 \pm 0,07$ & $49,38 \pm 3,95$ & $2,01 \pm 0,15$ \\
\hline 6. & $15 \mathrm{M}-25 \mathrm{M}$ & $1,57 \pm 0,06$ & $49,20 \pm 4,96$ & $1,94 \pm 0,19$ \\
\hline 7. & $25 \mathrm{M}-35 \mathrm{M}$ & $1,67 \pm 0,06$ & $49,47 \pm 6,35$ & $2,05 \pm 0,23$ \\
\hline \multicolumn{5}{|c|}{ Брас } \\
\hline 8. & винирювання-15 м & $2,04 \pm 0,37$ & $64,26 \pm 12,48$ & $1,92 \pm 0,20$ \\
\hline 9. & $15 \mathrm{M}-25 \mathrm{M}$ & $1,46 \pm 0,08$ & $61,32 \pm 7,04$ & $1,43 \pm 0,17$ \\
\hline 10. & $25 \mathrm{M}-35 \mathrm{M}$ & $1,58 \pm 0,12$ & $60,85 \pm 7,26$ & $1,56 \pm 0,14$ \\
\hline 11. & $45 \mathrm{M}-50 \mathrm{M}$ & $1,24 \pm 0,02$ & $59,82 \pm 7,42$ & $1,28 \pm 0,13$ \\
\hline \multicolumn{5}{|c|}{ Батерфляй } \\
\hline 12. & старт-винирювання & $1,96 \pm 0,22$ & - & - \\
\hline 13. & $25 \mathrm{M}-35 \mathrm{M}$ & $1,84 \pm 0,20$ & $59,92 \pm 4,06$ & $1,86 \pm 0,34$ \\
\hline 14. & $35 \mathrm{M}-45 \mathrm{M}$ & $1,81 \pm 0,12$ & $57,54 \pm 6,87$ & $1,91 \pm 0,33$ \\
\hline 15. & $45 \mathrm{M}-50 \mathrm{M}$ & $1,10 \pm 0,51$ & $51,47 \pm 4,76$ & $1,25 \pm 0,39$ \\
\hline
\end{tabular}

\section{Висновки / Дискусія}

Отримані результати погоджуються з твердженням багатьох авторів про те, що показники техніко-тактичної майстерності суттєво впливають на результат подолання дистанції 50 метрів незалежно від способу плавання.

Визначено, що найбільш впливовими на результат подолання спринтерської дистанції 50 метрів способом «кроль на грудях» $€$ параметри швидкості на ділянках «15 м - 25 м» та «45 м - 50 м» (R на рівні значень -0,60 та -0,72 відповідно), темпу гребкових рухів на відрізку «35 м - 45 м» $(R=-0,72)$.

Встановлено, що у способі «кроль на спині» результат більшою мірою залежить від швидкого пропливання перших 35 метрів змагальної дистанції (R знаходиться в межах -0, 57 - -0, 98), а також показників частоти рухів на ділянці «25 м- 35 м» $(R=-0,50)$.

Доведено, що при плаванні способом «брас» результативність на дистанції 50 метрів залежить від швидкості проходження відрізків «винирювання - 15 м» , «25 м - 35 м» та «45 м - 50 м» (R дорівнює -0,88, -0,56 та -0,86 відповідно), темпу на ділянках «винирювання 15 м» та «15 м - 25 м» (значення коефіцієнта кореляції сягає величин -0,55 та -0,70 відповідно), здатності зберігати значну довжину гребка в межах 15 - 35 метрів ( $\mathrm{R}$ знаходиться на рівні значень -0, $69-0,79)$.

3'ясовано, що результат в способі плавання «батерфляй» зумовлений швидкістю подолання спортсменками підводної ділянки та другої половини змагальної дистанції 50 метрів (R в межах 0,58 - 0,86). Темп i «крок» циклу гребкових рухів має тісний кореляційний зв'язок з кінцевим результатом на другій половині дистанції ( $\mathrm{R}$ знаходиться в межах від -0,70 до -0,97).

Орієнтація на розроблені модельні характеристики найбільш значущих техніко-тактичних показників висококваліфікованих спортсменок різної плавальної спеціалізації буде сприяти вдосконаленню тренувальної та змагальної діяльності у сучасному плаванні.

Перспектива подальших досліджень полягає у визначені особливостей техніко-тактичних дій спортсменок різних спеціалізацій при пропливанні дистанцій 100 та 200 метрів.

Конфлікт інтересів. Автори заявляють, що відсутній конфлікт інтересів, який може сприйматись таким, що може завдати шкоди неупередженості статті.

Джерела фінансування. Ця стаття не отримала фінансової підтримки від державної, громадської або комерційної організації. 


\title{
Список посилань
}

1. Гришин В.А.(2002), Дифференциация тренировочного процесса квалифицированных пловцов в зависимости от специализации : автореф. дис.... канд. пед. наук, Москва, 19 с.

2. Клешнев В. В. (2001), «Скорость, темп и шаг в плавании», Плавание, IV, Санкт-Петербург, С. 33 - 36.

3. Матвеев Л. П. (1996), Соревновательная деятельность спортсмена и система спортивных соревнований : учеб. пособие, Москва, 79 с.

4. Пилипко О. А. (2014), «Моделирование профиля высококвалифицированных спортсменок, специализирующихся в плавании способом кроль на груди», Науковий журнал «Science Rise», Харьков, № 3/1 (3), C. 78 - 86.

5. Пилипко О. О. (2018), «Моделювання показників техніко - тактичної майстерності висококваліфікованих спортсменів, які спеціалізуються в плаванні способом батерфляй на дистанції 50 метрів», Вісник Чернігівського національного педагогічного університету, Чернігів, Вип. 152, Т. 1, Серія: Педагогічні науки, С. 205 - 208.

6. Платонов В.Н. (2012), Спортивное плавание: путь к успеху : в 2 кн., Киев: Олимпийская литература, Кн. 1, 480 с.

7. Платонов В. Н. (2012), Спортивное плавание: путь к успеху : в 2 кн., Киев: Олимпийская литература, Кн. 2 , 544 с.

8. Подосинова Л. П., Евпак Н. А. (2015), «Повышение технической подготовленности квалифицированных пловцов на основании составления модельных характеристик», Фізична культура, спорт та здоров'я, Київ: НУФВСУ, С. 85 - 87.

9. Blanksby B., Nicholson L., Elliott B. (2001), «Biomechanical analysis of the grab, track and handle swimming starts: an intervention study», Sport biomechanics, V. 1, № 1, pp. 11 - 24.

10. Pilipko O. (2019), «Features of technical and tactical actions of highly skilled athletes when swimming a distance of 100 meters by front crawl», Slobozhanskyi herald of science and sport, Kharkiv, No 2 (70), pp. 31 - 36.

11. Haljand R. (1999), «Tehnical and tactical parameters of competition performances», Competition analysis in European Swimming Championships, Москва, pp. $1-7$.

12. Wilke K. (1997), Anfanger Schwimmen:training-technik-taktik, Rowohlt, 185 p.

Стаття надійшла до редакції: 10.11.2021 р.

Опубліковано: 23.12.2021 p.

\begin{abstract}
Аннотация. Ольга Пилипко, Алина Пилипко, Алина Шинкаренко. Определение модельных характеристик технико-тактических показателей высококвалифицированных пловчих, которые специализируются на дистанции 50 метров разными способами. Цель: разработать модельные характеристики технико-тактических показателей высококвалифицированных пловчих, которые специализируются на дистанции 50 метров разными способами. Материал и методы: анализ литературных источников, хронометрирование, видеосъёмка, методы математической статистики. Исследуемый контингент составили участницы финальных заплывов Чемпионатов и Кубков Украины по плаванию на дистанции 50 метров разными способами. Уровень спортивной квалификации спортсменок соответствовал званиям Мастер спорта Украины и Мастер спорта Украины международного класса. Результаты: исследовано влияние показателей скорости плавания, темпа и «шага» цикла гребковых движений на результат преодоления спортсменками высокой квалификации дистанции 50 метров разными способами; определены наиболее значимые параметры технико-тактического мастерства высококвалифицированных пловчих, в зависимости от способа плавания и разработаны их модельные характеристики. Выводы: влияние показателей скорости плавания, темпа и «шага» цикла гребковых движений на результат преодоления спортсменками высокой квалификации дистанции 50 метров имеет характерные особенности в зависимости от способа плавания. Наиболее значимыми технико-тактическими параметрами в способе плавания «кроль на груди» является скорость на участках «15 м - 25 м» и «45 м - 50 м», темп гребковых движений на отрезке «35 м - 45 м» (R равняется -0, 60, -0,72 и -0,72 соответственно). В «кроле на спине» результат преимущественно зависит от быстрого проплывания первых 35 метров дистанции (показатели $R$ находятся в пределах -0, 57 - -0, 98), а также значений темпа на участке «25 м - 35 м» (R= -0,50). Результативность на дистанции 50 метров при плавании способом «брасс» находится под влиянием показателей скорости преодоления отрезков «выныривание - 15 м», «25 м - 35 м» и «45 м - 50 м», темпа гребковых движений на участках «выныривание - 15 м» и «15 м - 25 м», способности сохранять большой «шаг» на отрезках «15 м - 25 м» и «25 м - 35 м» (R на уровне значений -0,88, -0,56, -0, 86, -0,55, -0,70, 0,79 и -0,69 соответственно). Результат в способе плавания «баттерфляй» в большей степени обусловлен скоростью прохождения подводного участка и второй половины дистанции 50 метров ( $R$ в пределах 0,58 - 0,86). Темп и «шаг» цикла гребковых движений тесно коррелирует с конечным результатом на второй половине соревновательной дистанции (значения $R$ варьируют от -0,70 до -0,97). Ориентация на разработанные модельные характеристики наиболее значимых показателей технико-тактического мастерства спортсменок высокой квалификации, имеющих разную плавательную специализацию, будет способствовать совершенствованию тренировочной и соревновательной деятельности в современном плавании.
\end{abstract}

Ключевые слова: спортсменки, 50 метров, способы плавания, технико-тактические показатели, взаимосвязь, модельные характеристики.

Abstract. Olha Pylypko, Alina Pylypko, Alina Shynkarenko. Determination of model characteristics of technical and tactical indicators of highly qualified female swimmers, who specialize on the distance of 50 meters by different strokes. Purpose: to develop the model characteristics of technical and tactical indicators of highly qualified female swimmers, who specialize on the distance of 50 meters by different strokes. Material and methods: analysis of literary sources, timing, video filming, methods of mathematical statistics. The surveyed contingent consisted of participants of the final heats of the Swimming Championships and Cups of Ukraine at the distance of 50 meters by different strokes. The level of sports qualifications of the sportswomen corresponded to the titles of Master of Sports of Ukraine and Master of Sports of Ukraine of international class. Results: the influence of indicators of swimming speed, tempo and «step» of the cycle of rowing movements on the result of overcoming the distance of 50 meters by different strokes by highly qualified sportswomen investigated; the most significant parameters of the technical and tactical skill of highly qualified female swimmers depending on the swimming stroke determined and their model characteristics developed. Conclusions: the influence of the indicators of swimming speed, tempo and «step» of the cycle of rowing movements on the result of overcoming the distance of 50 meters by highly qualified sportswomen has characteristic features depending on the swimming stroke. The most significant technical and tactical parameters in front crawl swimming is the speed on the segments « $15 \mathrm{~m}-25 \mathrm{~m}$ » and «45 $\mathrm{m}$ - $50 \mathrm{~m}$ », the tempo of the rowing movements on the sections «35 $m-45 m$ » ( $R$ is $-0,60,-0,72$ and -0,72 respectively). In the backstroke swimming 
the result mainly depends on the fast swimming of the first 35 meters of the distance ( $R$ values are in the range of $-0,57--0,98$ ), as well as the tempo values on the segment «25 $m-35 m$ » $(R=-0,50)$. Efficiency at the distance of 50 meters by breaststroke swimming is influenced by the speed indicators of overcoming the sections "emerging - $15 \mathrm{~m}$ ", " $25 \mathrm{~m}-35 \mathrm{~m}$ " and " $45 \mathrm{~m}-50 \mathrm{~m}$ ", the tempo of rowing movements on the segments «emerging - $15 m$ » and «15 $m-25 m$ », the ability to maintain a large «step» on the sections «15 $m$ - 25 $m$ » and «25 $m-35 m$ » ( $R$ at the level of values $-0,88,-0,56,-0,86,-0,55,-0,70,0,79$ and $-0,69$ respectively). The result in the butterfly stroke mostly depends on the fast passage the underwater area and the second half of the distance of 50 meters $(R$ within $0,58-0,86)$. The tempo and "step" of the cycle of rowing movements closely correlate with the final result on the second half of the competitive distance ( $R$ values vary from $-0,70$ to $-0,97$ ). Orientation on the developed model characteristics of the most significant indicators of technical and tactical skill of highly qualified female athletes, who have the different swimming specializations, will contribute to the improvement of training and competitive activity in modern swimming.

Keywords: sportswomen, 50 meters, swimming strokes, technical and tactical indicators, correlation, model characteristics.

\section{References}

1. Hryshyn, V. A. (2002), Differentiation of the training process of qualified swimmers depending on the specialization: Summary of candidate of pedagogical sciences dissertation. Moscow, 19 p. (in Russ.)

2. Kleshnev, V. V. (2001), «Speed, pace and step in swimming», Swimming IV, St. Petersburg, pp. 33 - 36. (in Russ.)

3. Matveev, L. P. (1996), Sorevnovatelnaia deiatelnost sportsmena y systema sportyvnykh sorevnovanyi : ucheb. posobye, [Competitive activity of the athlete and the system of sports competitions: textbook manual], Moscow, 79 p. (in Russ.)

4. Pylypko, O. A. (2014), "Modeling the profile of highly qualified athletes who specialize in swimming by the crawl stroke», Naukovyi zhurnal «Science Rise», Kharkov, № 3/1 (3), pp. 78 - 86. (in Russ.)

5. Pylypko, O. O. (2018), «Modeling of indicators in technical and tactical majesty of highly qualified athletes, who specialize in swimming with a butterfly stroke at a distance of 50 meters", Visnyk Chernihivskoho natsionalnoho pedahohichnoho universytetu, Chernigiv, Issue 152, Vol. 1, Ser: Pedahohichni nauky, pp. 205 - 208. (in Ukr.)

6. Platonov, V. N. (2012), Sportivnoe plavanie: put k uspekhu: v 2 kn. [Sports swimming: the path to success: in two books], Kiev, B.1, 480 p. (in Russ.)

7. Platonov, V. N. (2012), Sportivnoe plavanie: put k uspekhu: v 2 kn. [Sports swimming: the path to success: in two books], Kiev, B.2, 544 p. (in Russ.)

8. Podosynova, L. P., Evpak, N. A. (2015), «Improving the technical preparedness of qualified swimmers based on the compilation of model characteristics», Physical culture, sports and health, Kyiv: NUPhESU, pp. 85 - 87. (in Russ.)

9. Blanksby, B., Nicholson, L., Elliott, B. (2001), «Biomechanical analysis of the grab, track and handle swimming starts: an intervention study», Sport biomechanics, V. 1, № 1, pp. 11 - 24. (in Eng.)

10. Pilipko, O. (2019), «Features of technical and tactical actions of highly skilled athletes when swimming a distance of 100 meters by front crawl», Slobozhanskyi herald of science and sport, Kharkiv, No 2 (70), pp. 31 - 36. (in Eng.)

11. Haljand, R. (1999), "Tehnical and tactical parameters of competition performances», Competition analysis in European Swimming Championships, Moscow, pp. 1 - 7. (in Eng.)

12. Wilke, K. (1997), Anfanger Schwimmen: training-technik-taktik, Rowohlt, 185 p. (in Eng.)

Received: 10.11 .2021

Published: 23.12.2021

\section{Відомості про авторів / Information about the Authors}

Пилипко Ольга Олександрівна: к.пед.н., професор; Харківська державна академія фізичної культури: вул. Клочківська, 99, м. Харків, 61058, Україна.

Пилипко Ольга Александровна: к.пед.н., профессор; Харьковская государственная академия физической культуры: ул Клочковская, 99, г. Харьков, 61058, Украина.

Olha Pylypko: PhD (Pedagogical), Professor; Kharkiv State Academy of Physical Culture: Klochkivska 99, Kharkiv, 61058, Ukraine.

ORCID: https://orcid.org/0000-0001-8603-3206

E-mail: pilipkoolga@meta.ua

Пилипко Аліна Вікторівна: аспірантка; Харківська державна академія фізичної культури: вул. Клочківська, 99, м. Харків, 61058, Україна.

Пилипко Алина Викторовна: аспирантка; Харьковская государственная академия физической культуры: ул. Клочковская, 99, г. Харьков, 61058, Украина.

Alina Pylypko: graduate student; Kharkiv State Academy of Physical Culture: Klochkivska 99, Kharkiv, 61058, Ukraine.

ORCID: https://orcid.org/0000-0001-5637-9070

E-mail: alin4ik209@gmail.com

Шинкаренко Аліна Віталіївна: студентка; Харківська державна академія фізичної культури: вул. Клочківська, 99, м. Харків, 61058, Україна.

Шинкаренко Алина Витальевна: студентка; Харьковская государственная академия физической культуры: ул. Клочковская, 99, г. Харьков, 61058, Украина.

Alina Shynkarenko: student; Kharkiv State Academy of Physical Culture: Klochkivska 99, Kharkiv, 61058, Ukraine.

ORCID: https://orcid.org/0000-0002-3057-7666

E-mail: alina dn@i.ua 